\title{
The physician's role in cultivating healthful lifestyles
}

\author{
Yoni Freedhoff MD
}

See related CMAJ Open article at www.cmajopen.ca/content/4/2/E194

$\mathrm{L}$ ifestyle counselling is not the strong suit of primary care. In a recent research article in CMAJ Open, Bourgeois and colleagues found that clinicians perceived lack of time, expertise and competence as main barriers for lifestyle counselling designed to address the primary and secondary prevention of childhood obesity. ${ }^{1}$

Although the clinicians participating in the study cited time and their own lack of sensitivity and skills in exploring the topic of obesity prevention with young families, both they and the study's polled parents readily agreed that discussions around healthy living strategies were highly relevant. With the growing backdrop of childhood and adult obesity in Canada, and with lifestyle reported as being able to reduce the odds of developing our top killers - cancer, heart disease and diabetes - by as much as $80 \%,{ }^{2}$ the establishment of a road map to guide clinicians in cultivating healthful lifestyles among their patients is imperative to the health, and the health care expenditures, of our nation.

It is an interesting contradiction to see physicians identify a discussion as being highly relevant and yet cite time as the barrier to its initiation. Could this contradiction be due, at least in part, to a lack of training in nutrition and physical activity counselling?

A recent poll of medical students across nine Canadian universities showed overall dissatisfaction with their education on nutrition, with most students reporting a lack of comfort in discussing the role of nutrition in the treatment of disease and in identifying credible sources of nutrition education. ${ }^{3}$ Tellingly, and perhaps hearteningly, more than $87 \%$ of those polled believed that undergraduate medical education should dedicate more time to nutrition. Looking to the literature as to the state of medical education around physical activity, a recent study found that more than half of the physicians trained in the United States in 2013 received no formal education in physical activity and consequently are not prepared to counsel their patients adequately on engaging in activity. ${ }^{4}$

It is not likely enough simply to teach future clinicians about the whys and wherefores of healthful living. Health professionals have been found to possess dramatic weight biases; common stereotypes ascribed to those with obesity include laziness, lack of self-control, treatment noncompliance, dishonesty and lack of intelligence. ${ }^{5}$ In turn, this bias can affect patient care and undoubtedly jeopardizes the doctor-patient relationship. However, trust is integral to the acceptance of lifestyle counselling. Although it is not surprising that medical students have also been found to possess implicit anti-obesity biases, that $67 \%$ of the students were unaware of them ${ }^{6}$ speaks strongly to the need to ensure that medical education includes interventions designed to address these biases.

Although we have yet to devise a universally reproducible and effective office-based childhood obesity treatment and prevention program, there is some hope in that successful interventions, including those involving motivational interviewing, ${ }^{7}$ interprofessional counselling, ${ }^{8}$ parent-only counselling ${ }^{9}$ and more, ${ }^{10}$ have been identified. Nevertheless, when considering these successes, it is vital to remember that obesity is a chronic disease that requires lifelong treatment. Consequently, it is not surprising to find examples showing the recurrence of the disease when treatment stops. ${ }^{11}$

Obesity's chronic nature necessitates the involvement of primary care providers. Their role, unlike any other health care provider's, is one of lifelong, regular, consistent care. Ensuring that Canadian physicians receive training in the compassionate delivery of lifestyle guidance is crucial, and their guidance needs to be provided on a recurrent basis throughout a patient's care.

In their study, Bourgeois and colleagues ${ }^{1}$ identified an obvious window during which this discussion might begin: a gap in well-child primary care between two and five years of age, which
Competing interests: See end of article.

This article was solicited and has been peer reviewed.

Correspondence to: Yoni Freedhoff, drfreedhoff@ bmimedical.ca

CMAJ 2016. DOI:10.1503 /cmaj.160043 
corresponds to the immunization schedule in Ontario. Clinicians have reported this period as a time when families are seen less often, and when interventions may have the greatest benefit. ${ }^{12}$ Herein lies a window during which clinicians could purposefully explore lifestyle with the families of all of their patients, since room for improvement no doubt exists for children of every size, and primary prevention is perhaps the most valuable endeavour. During this time, appropriately trained clinicians could lay a foundation of knowledge that could then be regularly and briefly reinforced over time; these discussions would easily complement the current practice of routinely measuring each patient's height and weight.

Were we as a profession to make a concerted effort not only to recognize lifestyle as highly relevant, but also to train clinicians to help families with improving theirs, perhaps we could, at the very least, slow down the rise in chronic noncommunicable diseases such as obesity and, at best, help to start turning the tide.

\section{References}

1. Bourgeois N, Brauer P, Randall Simpson J, et al. Interventions for prevention of childhood obesity in primary care: a qualitative study. CMAJ Open 2016;4:E194-9.

2. Ford ES, Bergmann MM, Kroger J, et al. Healthy living is the best revenge: findings from the European Prospective Investigation into Cancer and Nutrition-Potsdam study. Arch Intern Med 2009; 169:1355-62.

3. Gramlich LM, Olstad DL, Nasser R, et al. Medical students' perceptions of nutrition education in Canadian universities. Appl Physiol Nutr Metab 2010;35:336-43.
4. Cardinal BJ, Park EA, Kim M, et al. If exercise is medicine, where is exercise in medicine? Review of US medical education curricula for physical activity-related content. J Phys Act Health 2015;12:1336-43.

5. Puhl RM, Luedicke J, Grilo CM. Obesity bias in training: attitudes, beliefs, and observations among advanced trainees in professional health disciplines. Obesity (Silver Spring) 2014;22:1008-15.

6. Miller DP Jr, Spangler JG, Vitolins MZ, et al. Are medical students aware of their anti-obesity bias? Acad Med 2013;88:978-82.

7. Resnicow K, McMaster F, Bocian A, et al. Motivational interviewing and dietary counseling for obesity in primary care: an RCT. Pediatrics 2015;135:649-57.

8. Hampl S, Odar Stough C, Poppert Cordts K, et al. Effectiveness of a hospital-based multidisciplinary pediatric weight management program: two-year outcomes of PHIT kids. Child Obes 2016;12:20-5.

9. Loveman E, Al-Khudairy L, Johnson RE, et al. Parent-only interventions for childhood overweight or obesity in children aged 5 to 11 years. Cochrane Database Syst Rev 2015;(12):CD012008.

10. Seburg EM, Olson-Bullis BA, Bredeson DM, et al. A review of primary care-based childhood obesity prevention and treatment interventions. Curr Obes Rep 2015;4:157-73.

11. Nyberg G, Norman $\AA$, Sundblom E, et al. Effectiveness of a universal parental support programme to promote health behaviours and prevent overweight and obesity in 6-year-old children in disadvantaged areas, the Healthy School Start Study II, a cluster-randomised controlled trial. Int J Behav Nutr Phys Act 2016;13:4.

12. Birch LL, Ventura AK. Preventing childhood obesity: What works? Int J Obes (Lond) 2009;33:S74-81.

Affiliation: Bariatric Medical Institute, Ottawa, Ont.

Competing interests: Yoni Freedhoff is the medical director and co-founder of the Bariatric Medical Institute, which receives funding from the Ontario Ministry of Health and Long-Term Care to deliver year-long childhood obesity treatment interventions to parents of children between 5 and 12 years of age whose weights are of concern. He is the author of The Diet Fix: Why Diets Fail and How to Make Yours Work. He is the clinical lead for the Centre for Effective Practice in the development of a new tool to help primary care providers in the primary and secondary prevention of childhood obesity.

\section{A credit to you!}

CMA members can earn CME credits for reading CMAJ articles

The CMAJ is committed to helping meet your accredited learning goals. CMA members can earn CME credits simply by reading the CMAJ. Selected CMAJ articles are eligible for Mainpro-M1 credits from The College of Family Physicians of Canada (CFPC). Members can also obtain Mainpro-M2 credits or MOC (Section 2) credits from Royal College of Physicians and Surgeons of Canada (RCPSC) for reading any article in CMAJ.

Learn more

www.cmaj.ca/site/cme

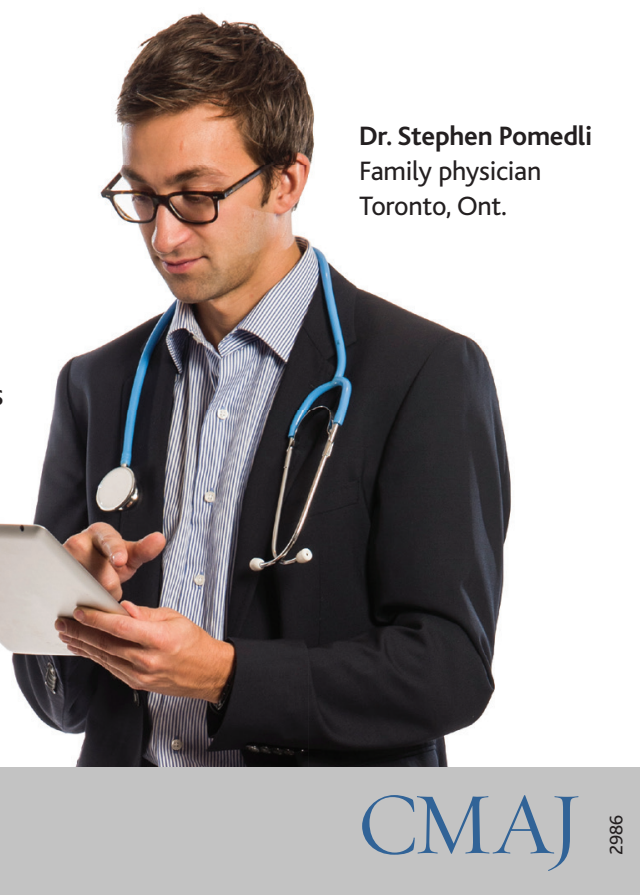

